\title{
Noonan syndrome with multiple lentigines
}

INSERM

\section{Source}

INSERM. (1999). Orphanet: an online rare disease and orphan drug data base. Noonan syndrome with multiple lentigines. ORPHA:500

Noonan syndrome with multiple lentigines (NSML), previously known as LEOPARD syndrome, is a rare multisystem genetic disorder characterized by lentigines, hypertrophic cardiomyopathy, short stature, pectus deformity, and dysmorphic facial features. 